\title{
DO PROJETO POLÍTICO-PEDAGÓGICO AO PLANEJAMENTO ESTRATÉGICO ESCOLAR
}

http://dx.doi.org/10.5902/2318133817081

\author{
Osvaldo Freitas de Jesus \\ Universidade de Uberaba, Brasil.
}

\begin{abstract}
Resumo
O projeto político-pedagógico - PPP -, feito como resposta à exigência dos artigos 12, 13, 14 e 15 da LDB/96, cumpriu seu papel na escola. Despertou o planejamento, a busca de identidade institucional e alguma inovação na educação. Mas ele se tornou um documento de pouco impacto, pois, depois de elaborado, o PPP não permaneceu como a referência. O projeto políticopedagógico foi mais o cumprimento de uma exigência legal, em vez de um planejamento estratégico da instituição. Assim, ele exerce pouca influência na vida concreta da gestão da escola. Já o planejamento estratégico escolar - PEE -, voltado para resultados no desempenho da escola, poderia ser uma resposta aos desafios educacionais atuais. A gestão escolar, centrada em resultados, pode trazer contribuições importantes para a escola.
\end{abstract}

Palavras-chave: planejamento político pedagógico, gestão escolar, planejamento estratégico escolar.

\section{FROM THE POLITICAL PEDAGOGICAL PROJECT TO THE SCHOOL STRATEGIC PROJECT}

\begin{abstract}
The pedagogical political project - PPP -, or the normative planning of the school, done as a response to the requirement of the articles 12, 13, 14 and 15 of the LDB/96, accomplished its role in school. It arose the collective planning, the search for institutional identity and some innovation in education. However, it lost its influencing power as a reference. The PPP turned out to be a legal obedience, instead of being a strategic dynamic planning for the institution. On account of this, its function in school has been questionable. The school strategic planning - SSP -, focusing on results and performance of the school could be the response for the actual problems of the school. The school management, focusing on results, though not popular, will certainly bring contributions to education.

Key-words: pedagogical strategic planning, school management, school strategic management.
\end{abstract}




\section{Introdução}

gestão, pública ou privada, em diferentes proporções, com menos ou maior
empenho, tem procurado maior eficiência no desempenho de suas funções
na sociedade. Desperdiçar, errar o alvo da produção, desconhecer o mercado e entregar produção imperfeita ao mercado soam como maldições no meio empresarial e produtivo. Como uma instituição, a escola pública também poderia se despertar para dar respostas mais eficientes ao mundo da educação no Brasil (Matias-Pereira, 2012, p. 21).

O projeto político-pedagógico, um planejamento normativo ${ }^{1}$, resultado da exigência da LDB/1996, artigos 12, 13, 14 e 15, prestou um enorme serviço à gestão escolar até recentemente. Entretanto, por ser mais uma resposta normativa, ele se tornou pouco influente nas mudanças efetivas da gestão da escola, em razão do que novas formas de planejamento começam a surgir. O planejamento estratégico, comum nas empresas, poderia ser adaptado às escolas, talvez se intitulando planejamento estratégico escolar. Longe de ser apenas normativo, ele seria mais um autocontrato de gestão, em razão do que sua força de realização poderia ser muito maior. Desde sua proposição até sua execução, o planejamento estratégico escolar passaria por quatro fases diferenciadas: 0 planejamento, a execução, o controle e a avaliação (Matias-Pereira, 2012, p. 127).

A possibilidade de tratar a gestão escolar como se fosse um fenômeno do mundo produtivo, naturalmente com algumas reservas, pode se tornar uma nova opção na administração pública. Sem dúvida, a escola não é uma empresa que produz objetos na linha de montagem, pois, em vez, ela forma sujeitos livres que conhecem e fazem opções na vida social. Essa mudança de visão pode ser resultado de programas avaliativos que têm sido implantados nos últimos governos federais, a saber, Sistema de Avaliação da Educação Básica - Saeb, Program International of Student Assessment - Pisa, Exame Nacional do Ensino Médio - Enem, Exame Nacional de Desempenho de Estudantes Enade, entre outros, os quais têm permitido a correlação entre gestão escolar e desempenho acadêmico dos alunos. Escola, cujo desempenho acadêmico dos alunos foi satisfatório, coincidentemente ou não, estava nas mãos de gestores mais empenhados na melhoria efetiva do funcionamento da instituição (Cunha, 2012).

Matias-Pereira (2012, p. 121) mostra que "a mudança fundamental no planejamento pode ser descrita como a transição de planejamento normativo, tradicionalmente adotado pelas organizações estatais até recentemente e o direcionamento para o planejamento estratégico que começa a ser discutido e adotado por tais organizações".

A gestão escolar, na instituição pública ou privada, pode aprimorar o planejamento escolar, sua execução e o alcance das metas desejadas. Ainda que o controle do governo sob a instituição pública seja enorme, mesmo assim resta alguma margem para superação desses cerceamentos. O ritmo da administração, as prioridades e a mobilização do pessoal pertencem ao diretor, sobretudo se ele for líder. Se, por um lado, o projeto político-pedagógico é uma peça textual que é elaborada e guardada na estante, o planejamento pedagógico estratégico é uma peça textual que requer planejamento, execução e avaliação ao final. Esse ciclo completo requer atenção e acompanhamento por parte dos gestores da instituição.

\footnotetext{
1 O termo normativo é utilizado nesse texto para designar o planejamento que é feito como resposta a obrigações criadas pelas normas vigentes e não pelo intuito de melhoria da gestão.

Regae: Rev. Gest. Aval. Educ. $\quad$ Santa Maria

v. 4

ก. 8

Jul./dez. 2015

p. $7-16$
} 
A Lei de Diretrizes e Bases, LDB/1996, nos artigos 12, 13, 14 e 15 determina que as escolas elaborem seu projeto pedagógico, de modo a assegurar em seu interior os valores democráticos, envolver a comunidade docente nos afazeres da escola, incrementar a qualidade da educação, fortalecer a identidade institucional e planejar o presente e o futuro. Nesses quatro artigos, designa-se por projeto pedagógico aquilo que hoje veio ser chamado de projeto político-pedagógico.

Depois de 18 anos de vigência da nova LDB, o projeto político-pedagógico, doravante PPP, pouco efeito surtiu na organização efetiva da escola. Seu impacto na vida da instituição foi insignificante, porque a organização e o desenvolvimento não são verdadeiramente funções da democracia. No máximo, a democracia é uma organização da vida política que permite o exercício da liberdade individual e coletiva, bem como a consolidação da economia de livre mercado. A escola no Brasil, em vista da busca de qualidade acadêmica, pode estar no limiar de um tempo novo de gestão.

\section{Projeto político-pedagógico}

Os artigos 12, 13, 14 e 15 da lei 9.394/96 estabelecem que a escola deve elaborar um projeto pedagógico, que the dê identidade, envolvendo os docentes, discentes, administrativos, pais e servidores. O art. 12, inciso I, é claro, ao ordenar que "os estabelecimentos de ensino, respeitada as normas comuns e as do seu sistema de ensino, terão a incumbência de; I. elaborar e executar sua proposta pedagógica."

Este artigo, na verdade, ainda que ordene a elaboração do projeto pedagógico, inclusive com prioridade dada ao inciso I, na verdade, está preocupado com outros sete incisos de não menor importância. O legislador, certamente, não antevia a importância que o projeto pedagógico viria conquistar na vida escolar.

Os artigos 13 e 14 requerem a participação docente e dos profissionais da educação, envolvidos na escola, respectivamente. Ainda muito marcante, o artigo 15 centra suas atenções na conquista da autonomia por parte da unidade escolar. Nos anos seguintes à promulgação da lei n. 9.394/96, a questão da democracia tornou-se o nó górdio das discussões escolares. A autonomia foi e ainda continua o sonho dourado da escola, mesmo sabendo que sua estrutura inteira esteve e continua engessada pelo ordenamento jurídico, advindo do governo federal, estadual e municipal.

Tendo emergido no momento pós-ditadura, a Constituição Federal, assim como a própria LDB, centraram seu foco na questão da liberdade, naturalmente em diferentes proporções. A Constituição Federal, no artigo 5, na sequência de 78 incisos, trata dos direitos fundamentais, garantindo sua modernidade, pois o indivíduo continua o centro das preocupações da sociedade moderna. A inclusão social tornou-se um grande esforço da modernidade para resgatar a divida social contraída anteriormente.

Com a entrada da nova LDB, nas palavras de Carneiro (2011, p. 22),

renasce a esperança da superação da cultura das ações educativas concorrentes, inaugurando-se um novo desenho de medidas de natureza estrutural inafastáveis, envolvendo gestão e financiamento da educação, estruturação curricular, formação do professor, atualização dos conteúdos e inovação metodológica e, por fim, encorporamento de sistema de ensino dinamicamente articulados. 
Nesse cenário de ocupação de novos espaços na educação, a LDB permitiu que a escola pudesse conjeturar novas dimensões identitárias para si, assim como contratar novas funções na vida da sociedade. Por ser uma unidade com contornos institucionais claros, muito semelhantes àqueles de uma empresa do mercado produtivo, mas guardando diferenças fundamentais, a escola vem buscando o próprio amadurecimento e função clara na sociedade.

O projeto político-pedagógico é a expressão mais viva desse novo momento da educação nacional. Juntar a comunidade acadêmica escolar ao redor de um projeto pedagógico que persiga a educação como um modo de ser democrático com suas implicações de liberdade e de deveres sociais, é um desafio para esta e para as próximas décadas. Talvez o desaguar dessas marés educacionais seja mesmo o planejamento estratégico escolar.

\section{Planejamento estratégico}

O planejamento de uma instituição escolar compõe-se de vários níveis distintos, adaptáveis aos fins a que ele se propõe. Ele pode ser subdivido em três tipos diferentes: estratégico, tático e operacional. Segundo Oliveira (2010), esses níveis ficariam assim distribuídos na pirâmide organizacional.

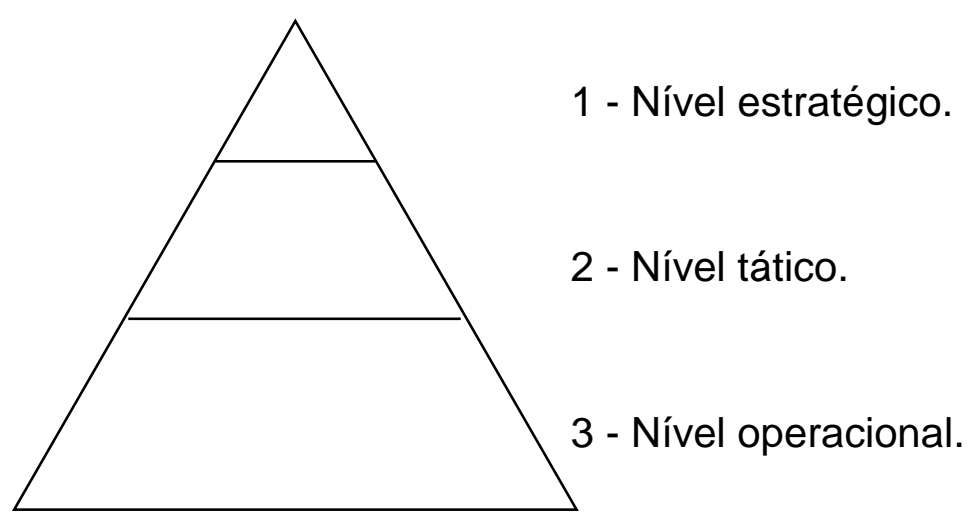

No primeiro nível, o estratégico, a instituição escolar procura quais fins e metodologias deve escolher e estabelecer, para se por na direção mais apropriada nos tempos seguintes, levando em conta a interação com fatores externos, tais como: governo, concorrentes, famílias, mercado de trabalho, entre outros. O planejamento estratégico é da competência do alto escalão da instituição escolar.

No segundo nível, o tático, a instituição escolar escolhe uma de suas áreas funcionais a receber apoio especial, por ser parte de seu planejamento estratégico. A área financeira, o corpo docente e técnico, o corpo discente, o mercado de trabalho, as famílias e a organização da instituição podem ser alvo de mudança, investimento e melhoria, em consonância com o planejamento estratégico (Oliveira, 2010).

No terceiro nível, o operacional, a instituição escolar produz documentos escritos que servirão de suporte e norte para o planejamento estratégico e tático estabelecido. Nesse momento, são previstos os recursos necessários para alcançar as metas propostas. Do mesmo modo, são os procedimentos básicos a serem adotados, tais como, 
os resultados esperados ao final, os prazos combinados e os responsáveis pelo acompanhamento das etapas que comporão as realizações da instituição.

Traçado o rumo maior, resultado de uma escolha consciente da instituição escolar, uma agenda de longo prazo é estabelecida, a qual absorverá toda a atenção e esforço dispendido no tempo presente e futuro. Esse compromisso institucional mobiliza os potenciais da organização como um todo para alcançar os fins propostos, contando com os recursos disponíveis. O planejamento estratégico tem um alcance longitudinal na instituição escolar, o que implica em abandonar mudanças recorrentes, como aquelas que são resultado de alternância política.

De não menor importância, a priorização de alguma área interna para investimento e apoio é decisiva, sabendo que ela deve ser estratégica para a consecução das metas maiores estabelecidas. Por exemplo, se o investimento maior for colocado na formação continuada do corpo docente, para melhorar o desempenho dos alunos nas avaliações acadêmicas estabelecidas pelo governo federal, a instituição escolar deverá fazer adaptações em vários setores internos. O calendário, os recursos humanos, financeiros e pedagógicos estarão implicados de maneira especial.

\section{Nova postura da escola}

Em países como a Inglaterra e País de Gales, o planejamento estratégico tornou-se comum nas escolas:

O planejamento estratégico é um processo-chave no gerenciamento, que engloba valores e objetivos institucionais e fornece a estrutura para desenvolvimento da qualidade de provisão e da destinação dos recursos. Até os anos de 1990, o planejamento estratégico, tanto para escolas como para educação adicional na Inglaterra e no País de Gales, foi conduzido em grande parte no nível de autoridades locais do sistema educacional. (Preedy, 2006, p. 13)

A abertura para uma gestão escolar mais eficiente permitiria à escola se conduzir com mais chances de sucesso no mercado das instituições escolares, sem que ela mesma se tornasse uma empresa do setor produtivo. Sua função social seria uma diferença capaz de não a deixar se fundir com as empresas produtivas.

O projeto político-pedagógico, um documento que se assemelha a um projeto normativo, como resposta requerida pela LDB, já cumpriu seu papel de ser transição para um planejamento mais profissional da gestão escolar. O preconceito que a escola tinha contra a empresa vem se obnubilando e uma nova clareira vem surgindo no horizonte: a escola pode ser bem melhor gerida para o bem de todos, envolvidos e da sociedade ampla.

As conquistas democráticas, para serem fortalecidas, exigem correção de rumos, adequações de estratégias políticas e, sobretudo, mudança de autoimagem. A escola não é mais uma instituição localizada nos mosteiros, paróquias e cortes (Tardiff, 2008), mas, sobretudo, uma instituição posta no mercado de trabalho competitivo e dinâmico, a qual a sociedade não pode dispensar.

Como bem aponta Veiga (2011, p. 41), "a administração da educação no Brasil, em nome da racionalização, tem oscilado entre ênfases na burocratização, na tecnocracia, na 
estrutura escolar e na gerência de verbas, com maio ou menor centralização e com todas as variações do uso das leis, das máquinas e dos modelos". Esse ciclo parece estar exausto, em razão do que novas maneiras de gerir a escola na sociedade devem surgir. Aqueles que chegarem à fonte à frente, beberão água límpida e cristalina.

Matias-Pereira (2012), inspirado em Bresser Pereira (1998), mostra os contrastes da gestão pública burocrática e morosa e os mecanismos de agilidade da administração pública moderna.

Quadro 1 -

Contraste entre modelos de administração pública.

\begin{tabular}{|c|c|}
\hline Admi & Admi \\
\hline $\begin{array}{l}1 \text { - Apoia-se na noção geral de interesse } \\
\text { público. } \\
2 \text { - Garante o cumprimento de } \\
\text { responsabilidade. } \\
3 \text { - Obedece às regras e aos } \\
\text { procedimentos. } \\
4 \text { - Opera sistemas administrativos. } \\
5 \text { - Concentra-se no processo. } \\
6 \text { - É autorreferente. } \\
7 \text { - Define procedimentos para contratação } \\
\text { de pessoal, compra de bens e serviços. } \\
8 \text { - Satisfaz as demandas dos cidadãos. } \\
9 \text { - Controla procedimentos. } \\
10 \text { - Define cargos rígida e } \\
\text { fragmentadamente. Tem alta } \\
\text { especialização. }\end{array}$ & $\begin{array}{l}1 \text { - Procura obter resultados valorizados } \\
\text { pelos cidadãos. } \\
2 \text { - Gera accountability. Eleva as relações } \\
\text { de trabalho. } \\
\text { 3- Compreende e aplica normas. Identifica } \\
\text { e resolve problemas. Melhora } \\
\text { continuamente os processos. } \\
4 \text { - Separa serviços e controle. Cria apoio e } \\
\text { normas. Amplia a escolha do usuário. } \\
\text { Encoraja ação coletiva. Cria incentivos. } \\
\text { Define, mede e analisa resultados. } \\
5 \text { - Orienta-se por resultados. } \\
6 \text { - Foca o cidadão. } \\
7 \text { - Luta contra o nepotismo e a corrupção. } \\
8 \text { - Evita adotar procedimentos rígidos. } \\
9 \text { - Define indicadores de desempenho. } \\
\text { Utiliza contratos de gestão. } \\
10 \text { - E multifuncional. Flexibiliza as relações } \\
\text { de trabalho. }\end{array}$ \\
\hline
\end{tabular}

Fonte: Bresser Pereira (1988); Pacheco (2003); Matias-Pereira (2010d), com adaptações.

Nesse quadro não é difícil perceber as diferenças existentes entre a administração pública burocrática e a gerencial. A segunda tem como centro o cliente, enquanto a primeira escolhe a si mesma para servir. Mais ainda, a burocrática permite o nepotismo, além de não ter mecanismos que inibam e controlem a corrupção. Apenas essas razões elencadas permitem dizer que o modelo gerencial está mais apto para lidar com os problemas do dia a dia moderno. 
Aplicado à escola pública, o modelo gerencial poderia melhorar o funcionamento da escola, inclusive servindo melhor a sua clientela: os alunos e pais. Atualmente a escola pública pode pouco, quando se pensa em serviços mais qualificados.

\section{Considerações finais}

O planejamento normativo, expressão utilizada anteriormente nesse texto, veio como uma resposta a uma exigência oficial do Estado, ou seja, o PPP, na sua origem, surgiu como uma carta de intenções, às vezes inócua na instituição escolar. Em vez de provocar a formação de uma identidade crítica da escola que o elaborou, o PPP se acomodou como uma resposta legal a uma exigência da LDB.

Em uma direção diversa, o planejamento estratégico escolar surge para realizar mudanças estruturais na instituição, esclarecendo sua identidade, estabelecendo metas factíveis de busca, revisando-se regularmente, checando erros e corrigindo desvios ocorridos. Por ser dinâmico e constante no funcionamento da instituição, o planejamento escolar estratégico não é uma resposta a uma exigência de normas do governo, mas, sobretudo, uma resposta aos novos desafios da sociedade moderna nesse mercado competitivo. Por exemplo, melhorar o desempenho acadêmico dos alunos nos próximos anos.

Tabela 1 -

Anos iniciais do ensino fundamental.

\begin{tabular}{c|c|c|c|c|c|c|c|c|c|c}
\hline \multirow{2}{*}{ Total } & \multicolumn{9}{c|}{ Ideb observado } & \multicolumn{6}{c}{ Metas } \\
\cline { 2 - 13 } & 2005 & 2007 & 2009 & 2011 & 2013 & 2007 & 2009 & 2011 & 2013 & 2021 \\
\hline \multicolumn{8}{|c|}{ Dependência administrativa } \\
\hline Estadual & 3.9 & 4.2 & 4.6 & 5.0 & 5.2 & 3.9 & 4.2 & 4.6 & 4.9 & 6.0 \\
\hline Munic. & 3.4 & 4.0 & 4.9 & 5.1 & 5.4 & 4.0 & 4.3 & 4.7 & 5.0 & 6.1 \\
\hline Privada & 5.9 & 6.0 & 6.4 & 6.7 & 4.9 & 3.5 & 3.8 & 4.2 & 4.5 & 5.7 \\
\hline Pública & 3.6 & 4.0 & 4.4 & 4.7 & 6.7 & 6.0 & 6.3 & 6.6 & 6.8 & 7.5 \\
\hline
\end{tabular}

Fonte: Saeb e Censo Escolar.

Nos anos iniciais, o desempenho do aluno do ensino fundamental na escola pública, municipal ou estadual, diz por si só que é insatisfatório. Imaginar que a gestão da escola nesse nível seja uma das variáveis que influencia o desempenho não seria uma conjectura inútil. Pelo contrário, essas correlações devem ser feitas. 
Tabela 2 -

Anos finais do ensino fundamental.

\begin{tabular}{c|c|c|c|c|c|c|c|c|c|c}
\hline \multirow{2}{*}{ Total } & \multicolumn{9}{c|}{ Ideb observado } & \multicolumn{7}{c}{ Metas } \\
\cline { 2 - 12 } & 2005 & 2007 & 2009 & 2011 & 2013 & 2007 & 2009 & 2011 & 2013 & 2021 \\
\hline \multicolumn{8}{c|}{ Dependência administrativa } \\
\hline Estadual & 3.3 & 3.8 & 4.0 & 4.1 & 4.2 & 3.5 & 3.9 & 4.4 & 5.5 \\
\hline Munic. & 3.1 & 3.6 & 3.8 & 3.9 & 4.0 & 3.3 & 3.5 & 3.8 & 4.2 & 5.3 \\
\hline Privada & 5.8 & 5.8 & 5.9 & 6.0 & 5.9 & 5.8 & 6.0 & 6.2 & 6.5 & 7.3 \\
\hline Pública & 3.2 & 3.5 & 3.7 & 3.9 & 4.0 & 3.3 & 3.4 & 3.7 & 4.1 & 5.2 \\
\hline
\end{tabular}

Fonte: Saeb e Censo Escolar.

Nos anos finais do Ensino Fundamental, o desempenho dos alunos, conforme demonstra a tabela anterior, piora o nível. Os alunos da escola estadual, municipal e pública não conseguem se aproximar do desempenho dos alunos da escola privada. $A$ gestão, de novo, pode ser uma das variáveis ativas nesse processo.

Tabela 3 -

Ensino médio.

\begin{tabular}{c|c|c|c|c|c|c|c|c|c|c}
\hline & \multicolumn{9}{c|}{ Ideb observado } & \multicolumn{7}{c}{ Metas } \\
\cline { 2 - 12 } Total & 2005 & 2007 & 2009 & 2011 & 2013 & 2007 & 2009 & 2011 & 2013 & 2021 \\
\cline { 2 - 12 } & 3.4 & 3.5 & 3.6 & 3.7 & 3.7 & 3.4 & 3.5 & 3.7 & 3.9 & 5.2 \\
\hline \multicolumn{10}{c}{ Dependência administrativa } \\
\hline Estadual & 3.0 & 3.2 & 3.4 & 3.4 & 3.4 & 3.1 & 3.2 & 3.3 & 3.6 & 4.9 \\
\hline Privada & 5.6 & 5.6 & 5.6 & 5.7 & 5.4 & 5.6 & 5.7 & 5.8 & 6.0 & 7.0 \\
\hline Pública & 3.1 & 3.2 & 3.4 & 3.4 & 3.4 & 3.1 & 3.2 & 3.4 & 3.6 & 4.9 \\
\hline
\end{tabular}

Fonte: Saeb e Censo Escolar. Os resultados marcados referem-se ao Ideb que atingiu a meta.

Por fim, o desempenho do aluno no Ideb do Ensino Médio piora mais nos índices da escola municipal, estadual e pública. Impressionam os números, pois eles deterioram progressivamente, à medida que o aluno avança na educação escolar.

Em uma pesquisa realizada na Bahia, tomadas duas escolas públicas, regidas pelas mesmas normas, com alunos de nível social semelhante, elas tiveram desempenho bem diferenciado no Ideb. Cunha (2012, p. 157), na conclusão de seu texto, procura

entender como escolas regidas pelas mesmas regras, pela coordenação do mesmo sistema de ensino, com o alunado, que guarda características sociais semelhantes, desenvolvem modelos de gestão tão díspares e possuem indicadores de desempenho educacional tão contrastantes. Por seu turno, os achados desta pesquisa sobre esses modelos de gestão, quando comparados com seus respectivos valores, medidos através do Ideb, podem fornecer pistas para o estabelecimento da associação entre gestão escolar e desempenho educacional das escolas, mesmo baseandose em estudo de caso, como o desenvolvido nesta dissertação. 
Não restou alternativa à pesquisadora, senão aquela de admitir que a gestão escolar pode ser a variável capaz de explicar a diferença no desempenho dos alunos no Ideb nas duas escolas estudadas A gestão eficiente, por razões bastante óbvias, pode ser o fiel da balança, quando se trata de explicar o desempenho diferenciado dos alunos de duas escolas iguais em tudo, porém diferentes na forma de gestão da instituição.

Ao organizar o processo pedagógico de maneira mais eficiente, a gestão facilita a aprendizagem e o ensino, pois ela organiza a aprendizagem, á medida que as regras do jogo ficam mais claras. Ideias claras e distintas, como dizia René Descartes (1962), e disciplina nas ações, como pretendia Immanuel Kant, são estratégias comuns nas organizações eficientes. Como afirma o antigo adágio, contra facta, non argumenta, isto é, contra os fatos, não há argumentos que resistam. O planejamento estratégico escolar seria um instrumento adicional nas mãos do gestor disciplinado que cumpre metas $\mathrm{e}$ realiza aquilo que foi combinado com os colegiados da escola.

\section{Referências}

ARAÚJO, Luís César Garcia de; GARCIA, Adriana Amadeu. Gestão de pessoas. São Paulo: Atlas, 2010.

BRASIL. Saeb. Brasília: Inep, 2013.

PEREIRA, Luiz Carlos Bresser. Reforma do estado para a cidadania: a reforma gerencial brasileira na perspectiva internacional. São Paulo: 34; Brasília: Enap, 1998.

CARNEIRO, Moaci Alves. LDB fácil: leitura crítico-compreensiva. Petrópolis: Vozes, 2011.

CUNHA, Eudes de Oliveira. A gestão escolar e sua relação com os resultados do ldeb: um estudo em duas escolas municipais de Salvador. Salvador: UFBA, 2012. $172 f$. Dissertação (mestrado em Educação). Universidade Federal da Bahia, Faculdade de Educação.

DEMO, Pedro. A nova LDB: ranços e avanços. São Paulo: Papirus, 1997.

DESCARTES, Renê. Discurso do método. São Paulo: Difusão Européia do Livro, 1962.

KANT, Immanuel. Crítica da razão prática. São Paulo: Martim Claret, 2005.

MATIAS-PEREIRA, José. Finanças públicas: a política orçamentária no Brasil. São Paulo: Atlas, 2010.

MATIAS-PEREIRA, José. Manual de gestão pública contemporânea. São Paulo: Atlas, 2012.

MEDEL, Cassia Ravena Mulin de Assis. Projeto político-pedagógico: construção e implementação na escola. Campinas: Autores Associados, 2008.

OLIVEIRA, Maria Auxiliadora Monteiro (org.). Gestão educacional: novos olhares, novas abordagens. Petrópolis: Vozes, 2005.

OLIVEIRA, Djalma de Pinho Rebouças de. Planejamento estratégico: conceitos, metodologia e práticas. São Paulo: Atlas, 2010.

PACHECO, Reinaldo O. S. Administração pública gerencial: desafios e oportunidades para os municípios brasileiros. Gestão Estratégica do Município, 2003, p. 39-49.

PETERS, B. Guy. American public policy: promise and performance. Los Angeles: Sage Publications, 2013. 
PREEDY, Margaret et al. Gestão em educação: estratégia, qualidade e recursos. Porto Alegre: Artmed, 2006.

SILVA, Reinaldo Oliveira da. Teorias da administração. São Paulo: Pearson, 2013.

TARDIF, Maurice; LESSARD, Claude. O ofício de professor: história, perspectivas e desafios internacionais. Petrópolis: Vozes, 2008.

THEODOULOU, Stella Z; CAHN, Mathew A. Public policy: the essential readings. Boston: Pearson, 2013.

VEIGA, Ilma Passos Alencastro (org.). Projeto político-pedagógico da escola: uma construção possível. São Paulo: Papirus, 2011.

Osvaldo Freitas de Jesus é mestre em Linguística pelo Boston College, USA, doutor em Educação pela Unicamp, aposentado pela UFU e professor na Universidade de Uberaba.

Endereço: Rua José Miguel Saramago, 920 - 38408-222 - Uberlândia - MG - Brasil.

E-mail: freitasdejesus.osvaldo09@gmail.com.

Recebido em 1ㅇ de março de 2015.

Aceito em 7 de maio de 2015. 